\title{
Anterior instabilite: Yineleyen çıkık ve revizyon cerrahisi
}

\author{
Anterior instability: recurrent dislocation and revision surgery \\ Illker Eren ${ }^{1}$, Mehmet Demirhan² \\ ${ }^{1}$ İstanbul Üniversitesi, İstanbul Tıp Fakültesi, Ortopedi ve Travmatoloji Anabilim Dalı
${ }^{2}$ Koç Üniversitesi, VKV Amerikan Hastanesi, Ortopedi ve Travmatoloji Bölümü, İstanbul
}

Yineleyen omuz çıkıkları genç erişkin popülasyonu etkileyen ve ciddi kısıtlılık yaratan önemli bir sağlık sorunudur. ilk çıkıkların tedavisi halen tartışmalı olmakla birlikte, tekrarlayan çıkıklarda cerrahi uygulanması kabul gören bir yaklaşımdır. Ancak tedavinin doğru olarak yönlendirilmesi, eşlik eden komponentlerin doğru tanınması ve yöntemlerin doğru seçilmesi ile mümkündür. Yetersiz tanı ve tedavi sonucunda yineleyen çıkıklarla karşılaşıması kaçınılmazdır. Bu derleme, yineleyen öne omuz çıkıklarında güncel tanı ve tedavi yaklaşımını özetlemekte, başarısız tedaviye yol açan durumlara ışık tutmayı amaçlamaktadır.

Anahtar sözcükler: omuz çıkı̆̆; eklem instabilitesi
Recurrent shoulder dislocations are severe limitations affecting the young adult population creates a major health problem. Although treatment of first dislocation is still controversial, implementation of surgery is an accepted approach to recurrent dislocations. However, the correct orientation of the treatment is possible with the selection of the right components and the recognition methods associated with them. Recurrent dislocations may be inevitable as a result of inadequate diagnosis and treatment. This review summarizes the current diagnostic and therapeutic approach to the recurrent shoulder dislocations, and aims to shed light on the circumstances that lead to treatment failure.

Key words: shoulder dislocation; joint instability
$\mathbf{Z}$ orlu abduksiyon ve eksternal rotasyon, omuzda anterior subluksasyon yada dislokasyona, dolayısıyla anterior osseöz ve yumuşak dokularda yaralanmaya ve anterior instabiliteye neden olmaktadır. Anterior instabilite kavramı salt yumuşak doku yaralanmasını içeren Bankart lezyonundan kemik kaybının eşlik ettiği instabiliteye kadar uzanan geniş bir spektrumdur. Bu spektrumun tanınması, yaralanma şeklinin ve boyutunun anlaşılması, uygun tetkikler ile instabilitenin nedeninin ortaya konması tedavinin yönlendirilmesi ve ortaya çıkabilecek sorunların önüne geçilmesi açısından önemlidir.

Bu derlemede yineleyen çıkıklardaki tedavi prensipleri, yetersiz cerrahiye etki eden predispozan faktörler ve revizyon cerrahisi üzerine güncel bilgilerin aktarılması amaçlanmıştır.

\section{ANTERIOR INSTABILITE}

Geçtiğimiz on yıl içerisinde, özellikle atletlerde yapılan çalışmalar ile instabilite kavramı daha iyi anlaşılabilmiştir. İnstabilite tanımı hiperlaksite, subluksasyon ve dislokasyonu içeren bir spektrumdur. $\mathrm{Bu}$ çerçevede patoanatomi, etiyoloji ve instabilitenin yönünü içeren bir sınıflama yapılmıştır. Illk olarak Travmatik - Unidireksiyonel - Bankart - Cerrahi (TUBS) ve Atravmatik - Multidireksiyonel - Bilateral Rehabilitasyon - İnferior Kapsüler Kaydırma - Rotator Interval Kapatma (AMBRII) olarak iki gruba ayrılırken, atletler üzerinde yapılan çalışmalar ile Edinsel Instabilite - Aşırı Yüklenme - Cerrahi (AIOS) grubu da eklenmiştir.

TUBS grubunda problem majör bir travmatik yaralanma ile başlamakta ve subluksasyonlar ve dislokasyonlar tek yönde ortaya çıkmaktadırve hemen her zaman abduksiyon ve dış rotasyon zorlanması ile ortaya çıkar; inferior glenohumeral ligaman (IGHL) yaralanması ile karakterizedir.

Anteroinferior ligamentöz kompleksin glenoidden periost ile birlikte ayrılması klasik Bankart Lezyonu olarak adlandırımaktadır. ${ }^{[1,2]}$ Travmatik ilk çıkıklara

- Illetişim adresi: Prof. Dr. Mehmet Demirhan, Teşvikiye Cad. Bayer Apt. No:63/3 Nişantaşı, İstanbul

Tel: 0532 - 2123337 e-posta: demirhanms@gmail.com

- Geliș tarihi: 25 Haziran 2013 Kabul tarihi: 25 Ekim 2013 
sıklıkla eşlik eden yaralanma tipidir. ${ }^{[3,4]}$ Anteroinferior glenoid kenardan kemik fragmanın ayrıldığı lezyon "osseöz Bankart" olarak tanımlanmaktadır. Bu yaralanma glenoid defekti ortaya çıkarması nedeniyle yineleyen çıkıklar ve tedavide başarsızlığın ortaya çıkmasında önemlidir.

Hill-Sachs lezyonu, humerus başının posterolateral kenarında, çıkık sırasında ortaya çıkan ezilme yaralanmasını tanımlamaktadır. ${ }^{[5]}$ Travmatik ilk çıkıkların hemen hemen tamamına eşlik etmektedir. ${ }^{[3,4,6]}$ Humerus başının 1/3'ünden büyük, glenoide paralel seyreden defektler prognoz açısından önem taşımaktadır ve redislokasyonların ortaya çıkmasında önemli rolü vardır. ${ }^{[7]}$

AMBRII tanımı, ortaya çıkışında travmanın eşlik etmediği ve sıklıkla hipermobilite sendromları ile birlikte olan çıkıkları kapsamaktadır. Fizik muayene sırasında bilateral, hatta tüm eklemlerde bulunan laksite genellikle ortaya konabilir. Konservatif tedavinin başarısız olduğu hastalarda inferior kapsüler kaydırma ve rotator intervalin kapatılması önerilmektedir. ${ }^{[8]}$

Mikrotravmalara bağı glenohumeral instabilite (AIOS), AMBRII'den farklı olarak dominant tarafta ve tek taraflı olarak görülmektedir. Olayı başlatan majör bir travma yoktur ve abduksiyon - dış rotasyonda tekrarlayıcı travmaya bağlı olarak anterior kapsül yaralanmasına neden olmaktadır. ${ }^{\left[{ }^{[-13]}\right.}$ Anterior laksite, dejenerasyon ve yırtığın eşlik ettiği labral lezyonlar, sekonder sıkışmaya bağlı rotator manşet yırtıkları eşlik etmektedir. ${ }^{[14]}$

Glenoid konkavitesi ve korakoakromial ark, humerus başını stabilize eden tüm kuvvetlerle birlikte önemli bir role sahiptir. Cerrahi öncesinde instabilitenin arkasındaki neden açıkça ortaya konmalıdır: (1) Glenoidin osseöz bütünlüğünde mi yetersizlik mevcuttur? (2) Humerus başının santralizasyonunu sağlayan labralligamentöz komplekste mi yetersizlik vardır? (3) Başı glenoide bastıran kas gücü mü yetersizdir? (4) Eklem yüzeyinde ve bütünlüğünde $\mathrm{mi}$ yetersizlik vardır? Sorunun doğru olarak ortaya konması, doğru tedavinin anahtarıdır ve tedavi sonrasındaki problemlerin önüne geçilmesini sağlar. Bunun için mutlaka yeterli bir hikaye alınmalı, uygun fizik muayene ve tetkiklerle tanı konmalıdır.

\section{Hikaye ve fizik muayene}

Patolojinin anlaşılmasında hikayenin yeri önemlidir. Subluksasyon ya da dislokasyonun ilk ne zaman oluştuğu, nasıl ve hangi pozisyonda provoke olduğu dikkatle sorgulanmalıdır. Abduksiyon, ekstansiyon ve eksternal rotasyon ile ortaya çıkan semptomlar anterior instabiliteyi düşündürürken, fleksiyon, iç rotasyon ve adduksiyon ile ortaya çıkanlar posterior instabilite açısından anlamlıdır. Çıkıkların kendiliğinden mi yoksa müdahele ile mi redükte olduğu ve sıklığı sorgulanmalıdır. Jeneralize tonik-klonik nöbetler anterior ve posterior omuz dislokasyonu ve sonrasında gelişebilecek instabilite açısından önem taşımaktadır. Geçirilmiş nöbet ile ilişkili omuz çıkığı hikayesi alınmalıdır.

Fizik muayenede öncelikle hastadan hangi pozisyonda subluksasyon yada dislokasyonun ortaya çıktığını göstermesi istenir. Oturur pozisyonda $90^{\circ}$ abduksiyonda yapılan eksternal rotasyon ile korkutma testi ile çıkık mekanizması simüle edilerek semptomların ortaya çıkışı izlenir. Aynı hareket yatar pozisyonda tekrarlanır, semptomlar ortaya çıktığında kol posteriora doğru bastırılarak yapılan relokasyon testi anterior instabiliteyi doğrular. Yatar pozisyonda ve $90^{\circ}$ abduksiyonda, skapula fikse edilerek humerus başının öne ve arkaya doğru hareketi çekmece testi ile değerlendirilir. Her iki taraf arasında fark olması, veya muayene sırasında çekilecek aksiller grafi tanıyı destekler. Çekmece testi sırasında humerus başı glenoide doğru bastırıldığında, normalde glenoidin şekli ve labral yapı nedeniyle başın mediale translasyonu izlenmez ve direnç mevcuttur; Bankart lezyonu ya da glenoid konkavitesinin bozuk olduğu durumlarda mediale doğru kolaylıkla yer değiştirir (Load and Shift Test). Humerus başını glenoidin içinde tutan diğer önemli yapı kaslardır. Subskapularis, supraspinatus ve infraspinastusun kas güçleri mutlaka değerlendirilmelidir. Jeneralize laksite muayenesi, diğer eklemleri de değerlendirecek şekilde mutlaka yapılmalıdır. Laksitenin eşlik ettiği omuz instabilitelerinde tedavi ve rehabilitasyon prensipleri değişmektedir.

\section{Radyolojik değerlendirme}

Yaralanmanın ve instabilitede etkisi olan faktörlerin ortaya konması için doğru radyolojik değerlendirme esastır. Bu, ancak standart görüntülerin elde edilmesi ile mümkün olur. Skapula aksına dik çekilen gerçek AP grafi ile omuz çevresi yapıların osseöz anatomisi ve anterior glenoid çizgisi, apikal oblik grafi ile humerus başının posterolaterali ve anteroinferior glenoid kenar, humerus başının yerleşiminin, anterior humerus defektlerinin ve anterior-posterior glenoidin değerlendirildiği aksiller grafi ile osseöz yapılar görüntülenir.

Bunların yetersiz kaldığı durumlarda bilgisayarlı tomografi kemik yapısının değerlendirilmesi için oldukça yardımcıdır. Standart aksiyel, frontal ve sagittal planların dışında özellikle glenoidin üç boyutlu rekonstrüksiyonu, kemik defektlerinin ve osseöz yetersizliğin değerlendirilmesinde değerlidir (Şekil 1).

İnstabilitelerin büyük çoğunluğu labral-kapsüler yapının problemlerinden kaynaklanmaktadır. Bunların değerlendirilmesinde manyetik rezonans (MR) 


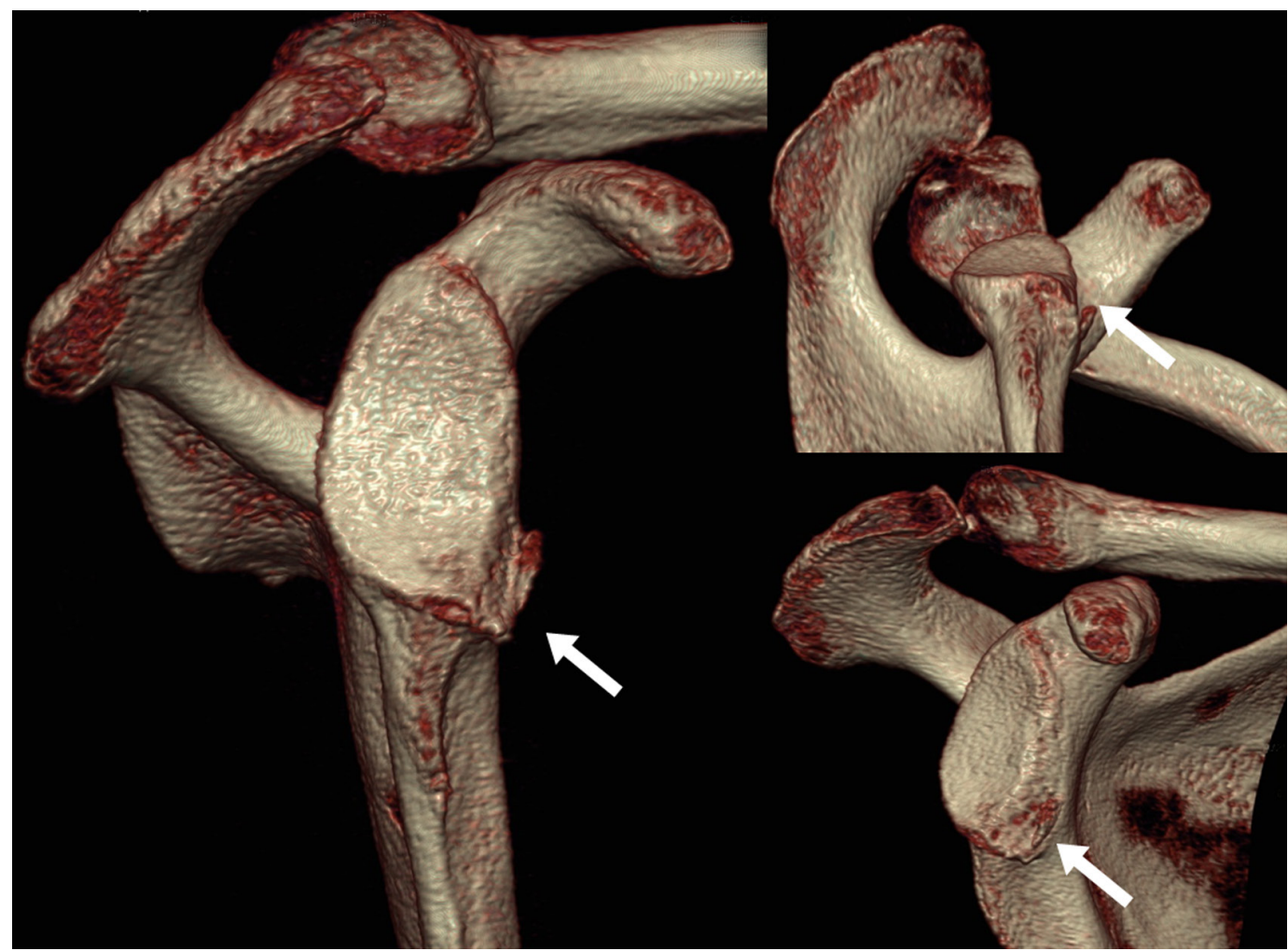

Şekil 1. Glenoid anteroinferior osseöz lezyonu, 3 boyut rekonstrüksiyonlu bilgisayarlı tomografi ile değerlendirilebilir (beyaz ok).

görüntülemenin yeri önemlidir. Eklem içi patolojilerin ve labral lezyonların tanısında arthro-MR'ın hassasiyeti, konvansiyonel MR'a göre yüksektir.

\section{Cerrahi teknik}

Artroskopik tekniklerin, kullanılan aletlerin gelişmesi ile birlikte son 10 yıl içinde açık cerrahi endikasyonları hızla azalmıştır. Son yıllarda yapılan geniş metaanalizler, birçok alanda açık cerrahi ve artroskopik cerrahinin sonuçları arasında fark olmadığına ve ancak bazı relatif kontrendikasyonlardan bahsedilebileceğine işaret etmektedir. ${ }^{[15,16]}$ Kas gücünün korunmasının cerrahi sonrasında başarıyla ilişkisi bilinmektedir. ${ }^{[17]}$ Açık cerrahi sonrasında daha uzun immobilizasyon ve yumuşak doku hasarı oluşması kas gücü kaybına yol açmaktadır. Bu açıdan artroskopinin üstün olduğu düşünülebilir. Bunun yanında artroskopinin de, sinir yaralanması, kondroliz veya patolojinin yetersiz tedavisi gibi bazı olumsuz yönleri mevcuttur. ${ }^{[18]}$ Bu nedenle açık cerrahi ve artroskopik cerrahi arasında seçim dikkatle yapılmalıdırOmuz artroskopisi için iki pozisyon tarif edilmiştir: Lateral dekübit ve şezlong pozisyonu. Şezlong pozisyonunun, kolun mobilize kalması, traksiyona bağlı nöropraksi riskinin olmaması, kapsüler anatominin pozisyona sekonder bozulmaması ve hızIı hazırlık gibi avantajları mevcuttur. Lateral dekübit pozisyon ise, traksiyon ile mobilize olan labruma ve inferior 1/3 labruma erişimde avantaj sağlamaktadır (Şekil 2). Son beş yıldır, pratiğimizde avantajları nedeniyle, lateral dekübit pozisyonunu tercih etmekteyiz.

\section{Bankart ve SLAP lezyonu}

Öncelikle diagnostik artroskopi yapılarak Bankart ve SLAP lezyonları ortaya konur. SLAP lezyonu sıklıkla bir başka intraartiküler patolojiye eşlik etmektedir. ${ }^{[19]}$

Kemik kaybının büyüklügünün ve Hill-Sachs lezyonunun anterior glenoid kenara takılıp takılmadığının değerlendirilmesi, direkt artroskopik olarak diğer görüntüleme yöntemlerine göre çok daha başarıyla yapılabilmektedir. Açık instabilite cerrahisi tercih edilse bile öncesinde diagnostik artroskopi yapılması önerilmektedir. ${ }^{[20]}$

Periosteal elevatör yardımı ile labroligamentöz kompleks superior ve inferiora doğru ayrılarak, labrumun istenilen şekilde yerleştirilmesi için mobilizasyon sağlanır. Glenoid kenar ve komşu skapula boynu yüksek devirli burr yardımıyla dekortike edilerek canlandırılır. 


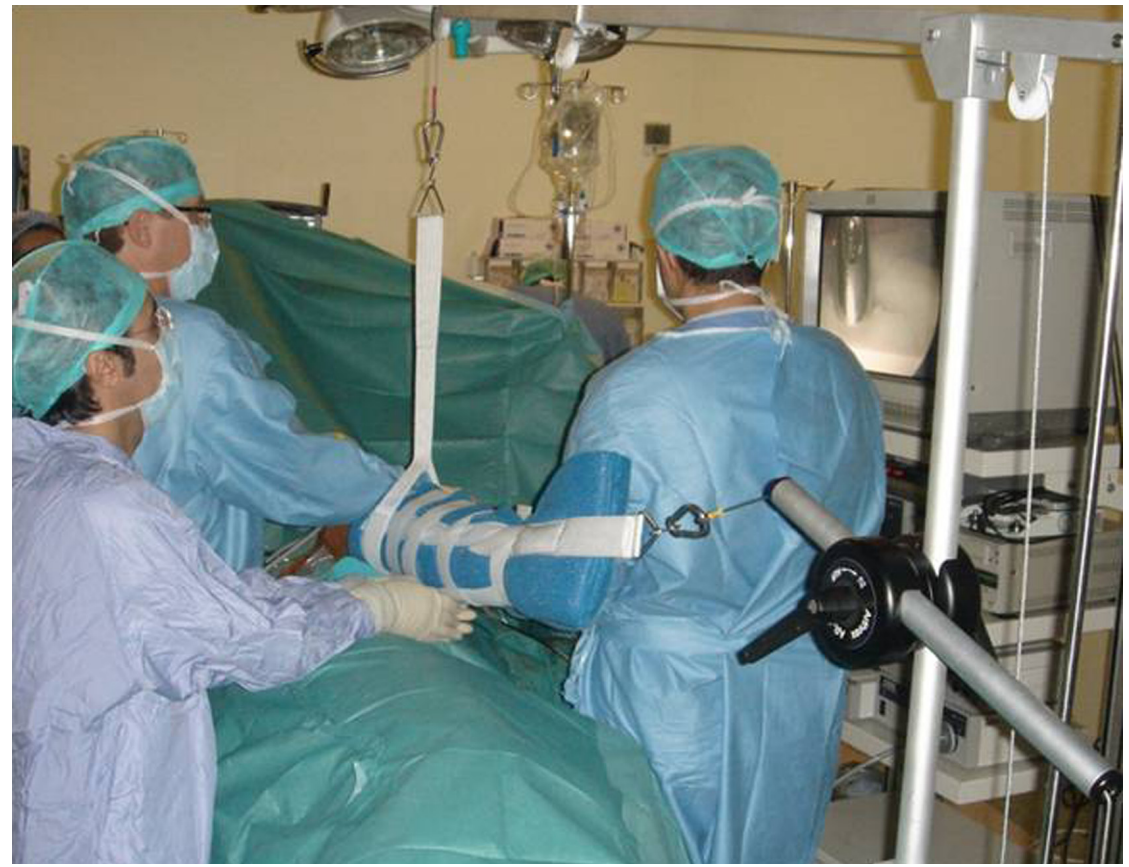

Şekil 2. Lateral dekübit pozisyonu ve traksiyon için kurulan düzenek.

SLAP lezyonu mevcutsa yumuşak doku traşlayıcı yardımıyla superior glenoid çevresindeki fibröz dokular temizlenir ve labrum çevresi hafifçe debride edilir. Burkhat ve ark.'nın tarif etiği yöntem yardımıyla, superior labrumdan geçirilen geçici-monoflaman sütür anterosuperior portalden dışarı alınarak superior labrum geçici olarak asılır. ${ }^{[21]}$ Burr yardımıyla biceps ve labrum altında kalan osseöz yapı traşlanır. Anterosuperior portal kullanılarak kıkırdağın hemen yanında, bicepsin altında kalacak şekilde çapanın gönderileceği nokta hazırlanır. Çift iplik, tek çapa kullanılarak posterior ve anterior labrum tespit edilir (Şekil 3). ${ }^{[22]}$ Geniş

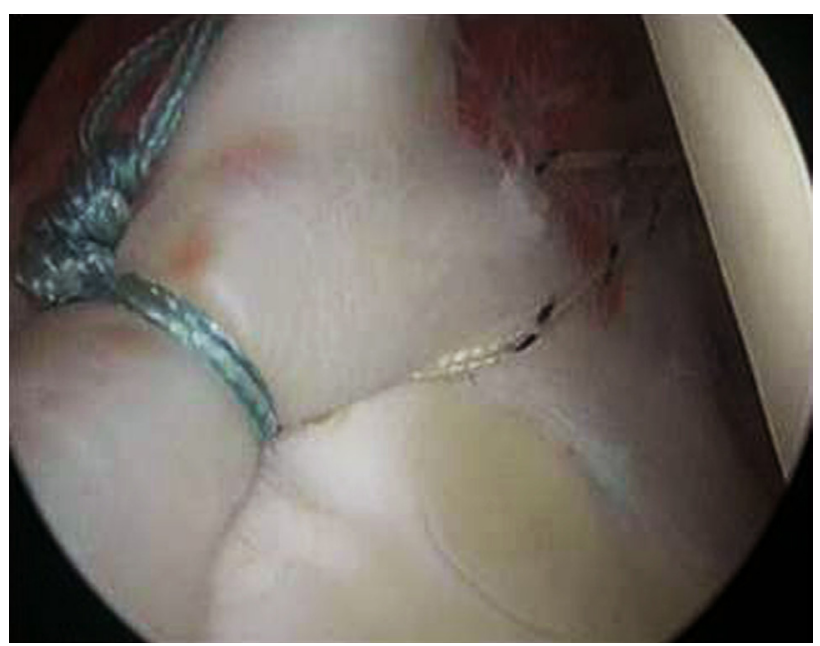

Şekil 3. Onarımı yapılmış SLAP lezyonu. lezyonlar için çift çapa kullanılmalıdır. Güncel yayınlar SLAP lezyonlarının konservatif takip edilebileceğini göstermekle birlikte başüstü atıcısı atletlerde mutlaka cerrahi tedavi yapılmalıdır (Şekil 4). ${ }^{[23]}$

Klasik anteroinferior portal ile çapa yerleşiminde saat 5 hizasına kadar inilmesi mümkün değildir. Bu yüzden saat 5 ve $5: 30$ portali tanımlanmıştır. ${ }^{24]}$ Saat $5: 30$ portali subskapularis içinden geçilerek açılır ve 5 hizasına çapa dik olarak yerleştirilebilir. Superiorundan ikinci çapa da yerleştirilerek stabilite test edilir. Gerek görülürse üçüncü çapa da yerleştirilebilir. Çapalar mutlaka glenoidin tam kenarına, kıkırdak sınırına yerleştirilmelidir ve saat 2:30 üzerine çıkmamalıdır. Artroskopik cerrahide ek portal kullanımının önemi büyüktür ve tarif edilen tüm portallerin avantajları iyi bilinmeli, gerektiğinde kullanmaktan kaçınılmamalıdır (Şekil 5).

Anterior ve posterior Bankart lezyonuna eşlik eden SLAP lezyonu bulunması halinde patoloji “üçlü labral lezyon" olarak tanımlanır ve labral lezyonların $\% 2,4$ 'ünü oluşturmaktadır. ${ }^{[25]}$

\section{Açık Latarjet prosedürü}

Latarjet prosedürü, anterior instabilitede üç farklı mekanizma ile işlev görmektedir: (1) Abduksiyon ve eksternal rotasyonda konjuant tendon, eklem kapsülü ve supskapularis üzerine askı mekanizması etkisi gösterir, (2) Glenoid antero-posterior çapı artar, (3) Kapsülün korakoakromial ligamanın güdüğüne onarımı stabilizan etki gösterir. 

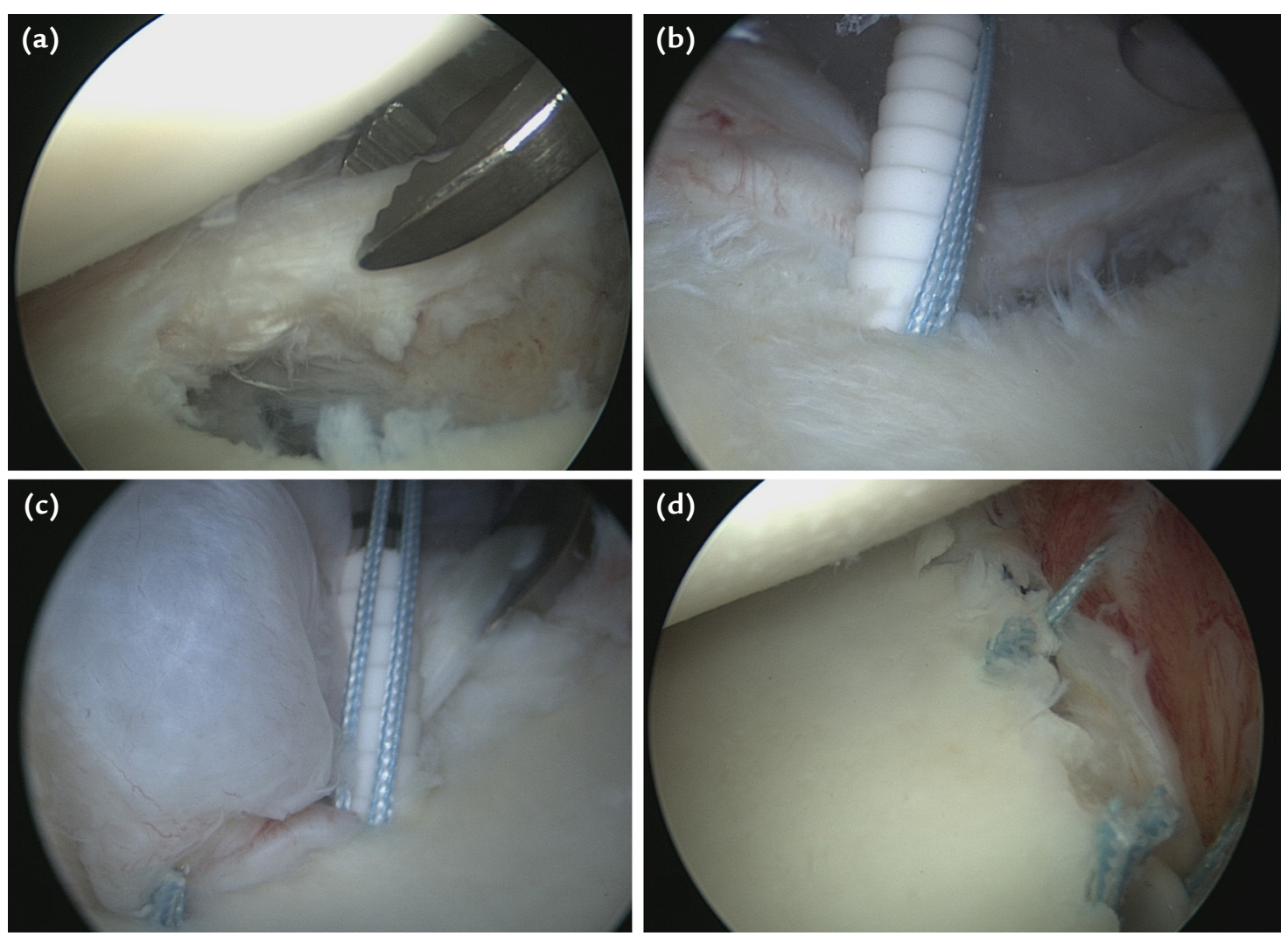

Şekil 4. a-d. İki çapa ile Bankart tamiri. Lezyonun tanımlanması ve yüzey hazırlığı (a); çapa yerleşimi (b, c); tamir sonrası artroskopik görünüm (d).

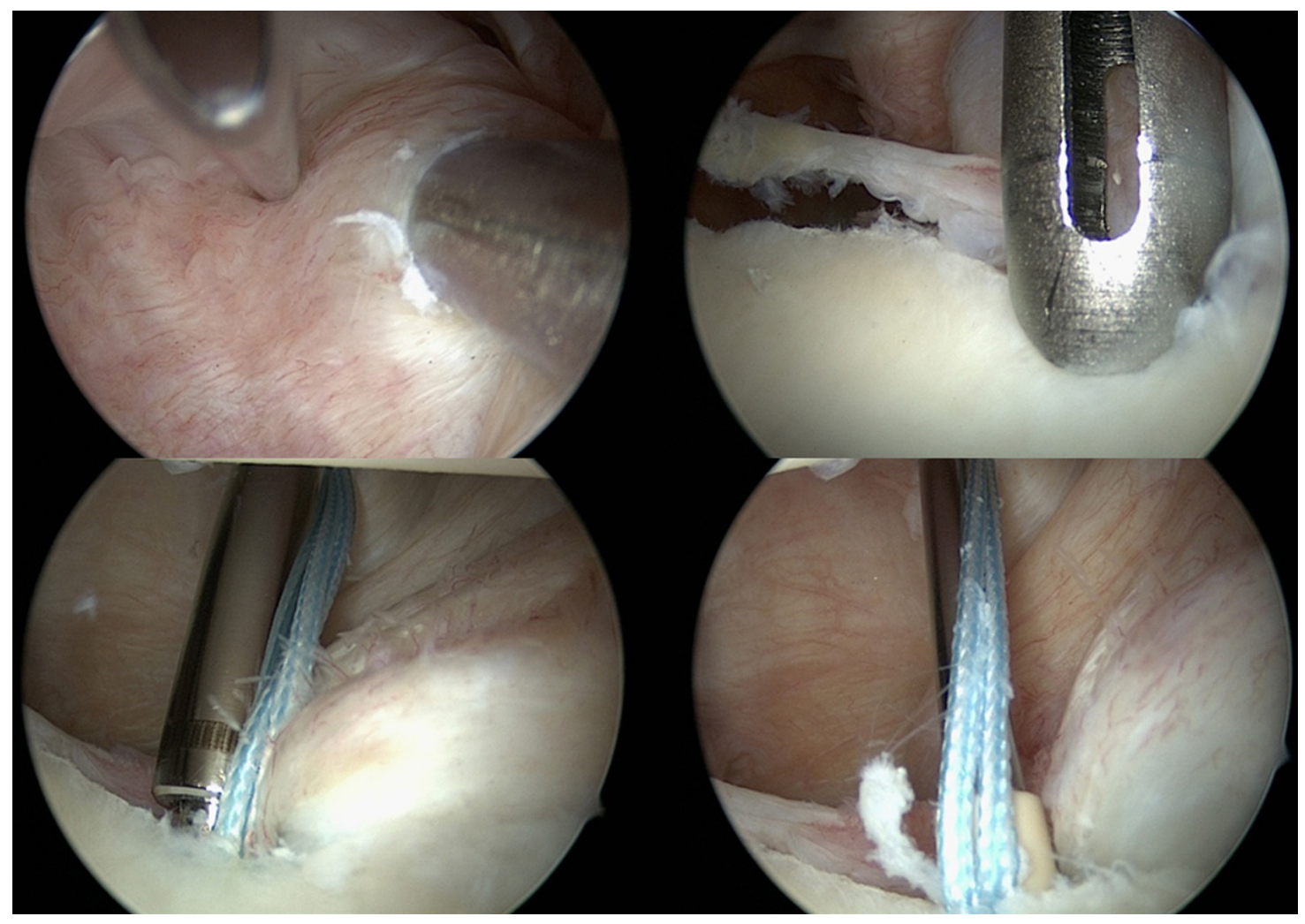

Şekil 5. Saat 5 portali kullanılarak inferior çapanın yerleştirilmesi. 

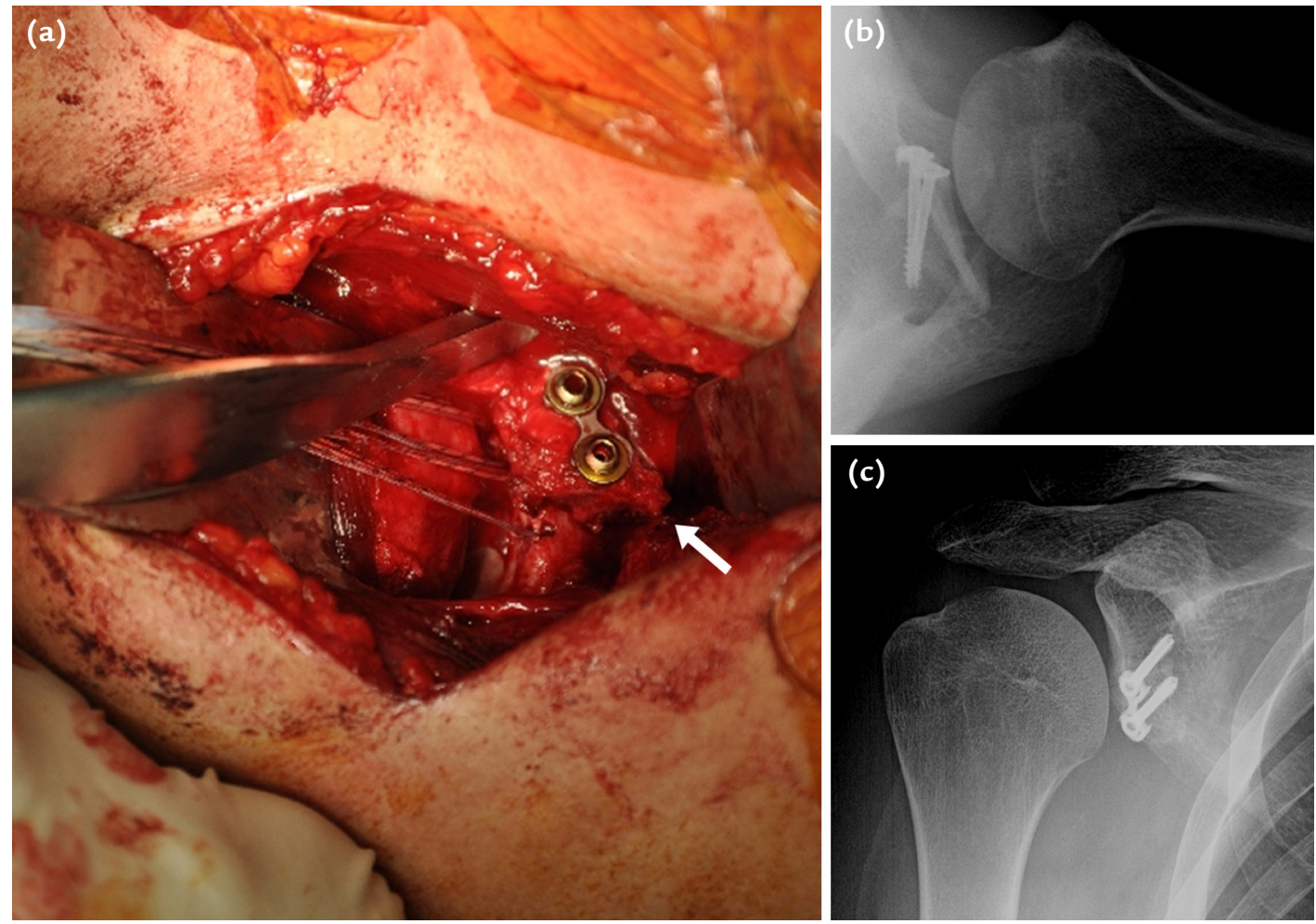

Şekil 6. a-c. Korakoid greftinin glenoid ön yüzüne plak ve 2 vida ile tespiti (a). Aynı hastanın ameliyat sonrası aksiller (b) ve gerçek AP (c) grafileri.

Hasta şezlong pozisyonunda hazırlanır. Korakoidin ucundan aksiller katlantıya doğru 4-5 cm'lik insizyon yapılır. Deltopektoral aralık kullanılarak derinleşilir. Kol abduksiyon ve eksternal rotasyona alınarak korakoid üzerine ekartör konur. Korakoakromial ligaman yapışma yerinden $1 \mathrm{~cm}$ distalden ayrılır ve altta yer alan korakohumeral ligaman gevşetilir. Kol adduksiyon ve internal rotasyona alınarak pectoralis minör hemen korakoid üzerinden ayrılır. Korakoidin alt kenarı çevre dokulardan ayrılarak, korakoidin proksimalindeki dirsek yaptığı bölüm görülür. Buradan korakoide dik olacak şekilde osteotomi yapılır. Alt kısmı tamamen dekortike edilir. Matkap ucu yardımıyla korakoidin ortasında kalacak ve aralarında yaklaşık $1 \mathrm{~cm}$ olacak şekilde iki delik açılır. Supskapularis tendonu üst ve alt uçları görülecek şekilde ortaya konur. Eklem içi olan superior kısım keskin bir şekilde ya da 1/3 alt kısımdan uzanımına paralel bir şekilde ayrılarak glenoide ulaşılabilir. Tendon yükseltildiğinde altta kalan kapsül görülebilir; 2 cm'lik vertikal insizyon ile ekleme ulaşılır. Anteroinferior labrum ve periost eksize edilir. Saat 2 hizasından 6 hizasına kadar yumuşak dokular uzaklaştırılmalıdır. Saat 4-5 hizasında alt delik açılır. Delik açılırken korakoidin glenoidden daha lateralde kalmamasına ve eklem yüzeyinde basamaklanma yaratmamasına dikkat edilmelidir. İki vida ya da mini plak ve iki vida kullanılarak tespit sağlanır (Şekil 6). 1-2 mm'lik medial yerleşim kabul edilebilir, ancak lateral yerleşimli olmamasına dikkat edilmelidir. Kol dış̧ rotasyona alınarak korakoakromal ligaman güdüğü kapsüle dikilerek onarılır ve kapsül kapatılır. Latarjet prosedürünün artroskopik olarak yapılması da mümkündür. ${ }^{[26]}$

Osseöz Bankart tedavisinde, cerrahi yöntem seçiminde, fragmanın büyüklüğü ve glenoid yüzeyindeki kayıp çok önemlidir. Glenoidin konkavitesi "konkavitekompresyon" adı verilen bir mekanizma ile stabilizasyona etki etmektedir. ${ }^{[27]}$ Bu yapıdaki osseöz yetersizlikler son yıllarda daha iyi anlaşılarak başarısız cerrahideki rolü aydınlatılmıştır. Her ne kadar glenoidde ne kadar kaybın yetersizliğe rol açtığı net olarak ortaya konmamış olsa da \%15-20 (5-7 mm)'nin altındaki kayıpların yumuşak doku girişimleri ile tolere edilebileceği, \%2530 üzerindeki $(6-8 \mathrm{~mm})$ kayıpların osseöz güçlendirmeye ihtiyacı olduğu literatürde kabul görmektedir. ${ }^{[28]}$ Yüzde 50 ve üzerindeki glenoid kayıplarında Latarjet prosedürü yeterli olmamaktadır ve iliak kanattan alınan strüktürel greft ile rekonstrüksiyon önerilmektedir (Şekil 7). ${ }^{[29]}$ Yanlızca büyüklük değil, fragmanın yerleşimi de önemlidir. Ters armut gürünümlü glenoid için modifiye Latarjet prosedürü tarif edilmiştir. ${ }^{[30]}$ 


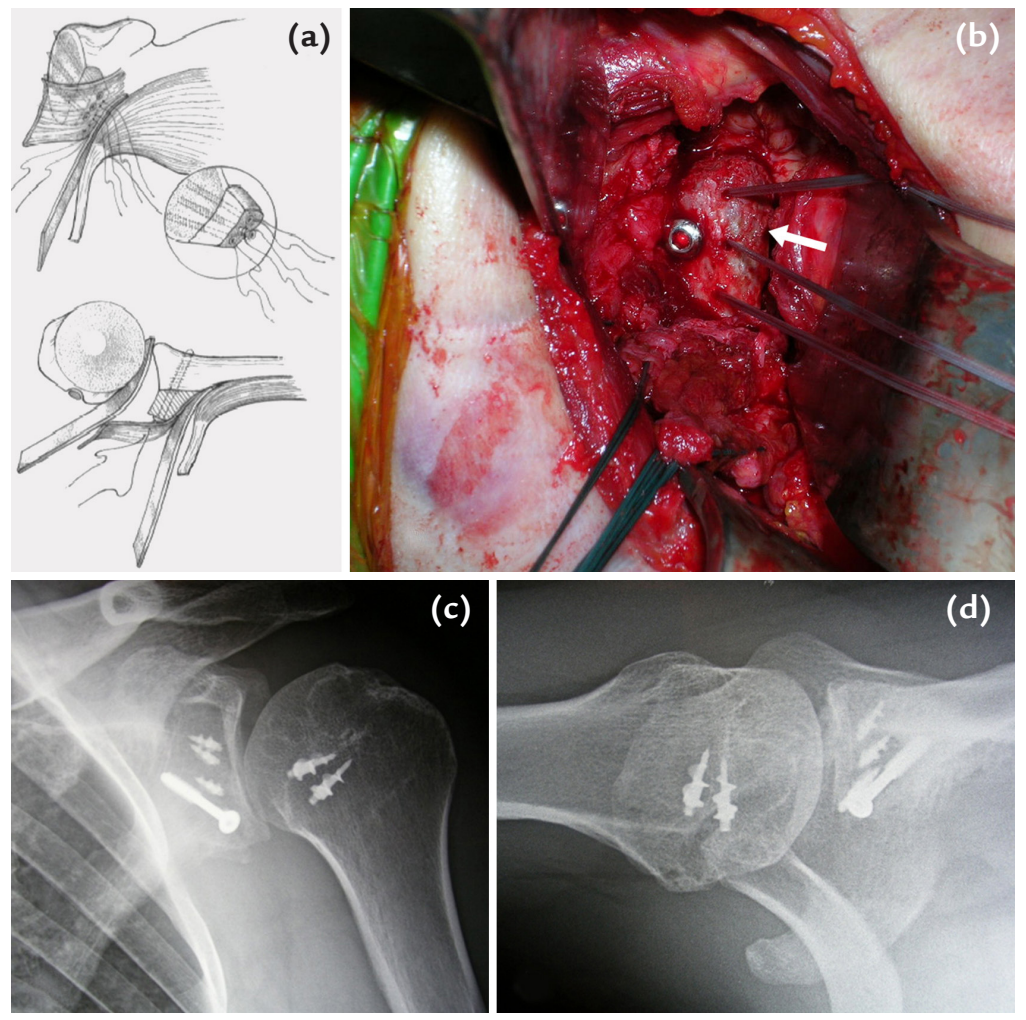

Şekil 7. a-g. İliak kanattan alınan strüktürel greft ile glenoid rekonstrüksyonu. Şematik çizimi (Warner ve ark.[29]) (a) ve greft içerisinden (beyaz ok) geçen sütürler ve vida ile tespiti görülmekte (b). Aynı hastanın ameliyat sonrası çekilen grafileri (c, d). Ameliyat sonrasında 2 . yıl takibinde hareket açıklığının tam olduğu görülüyor (e-g).
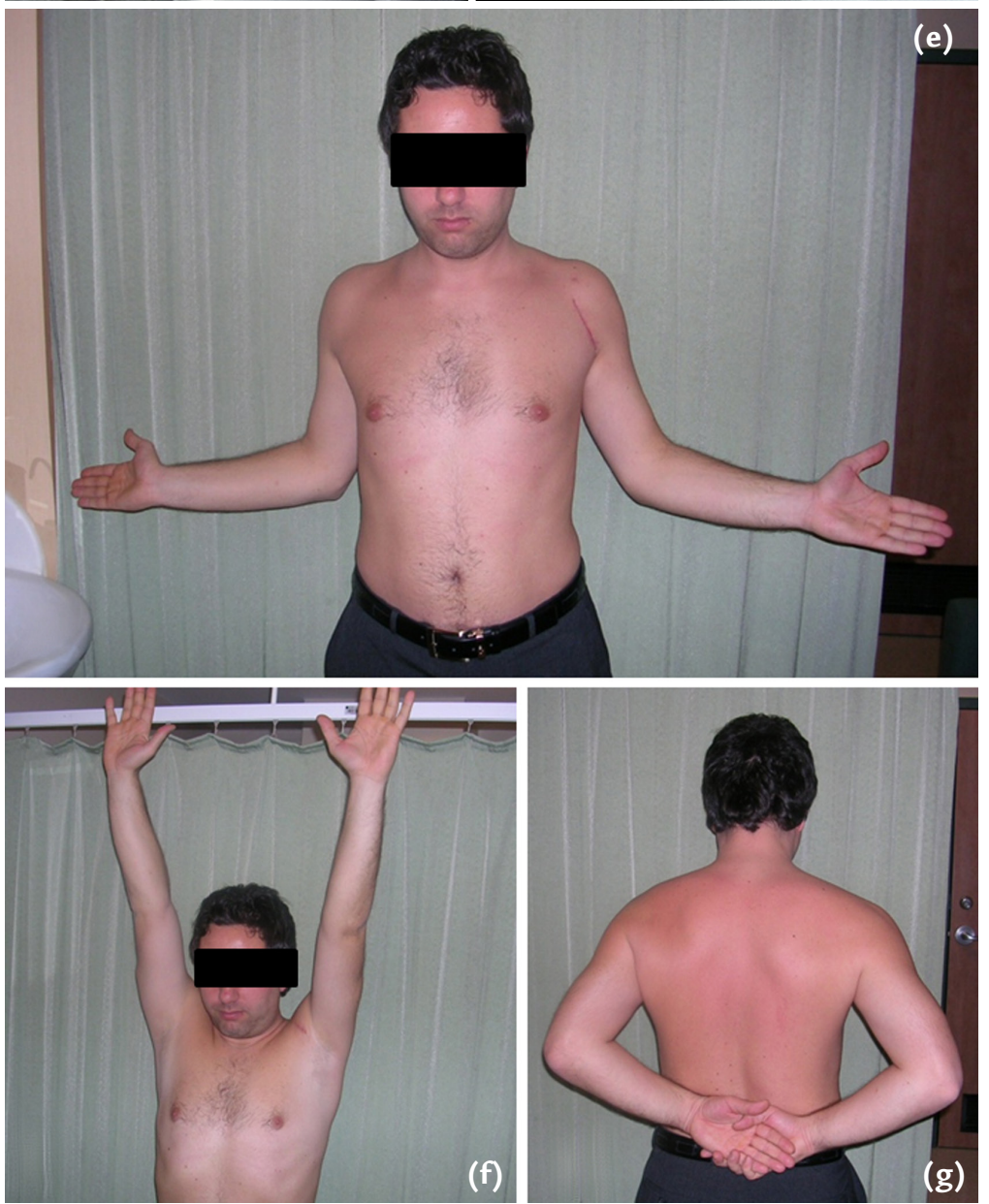

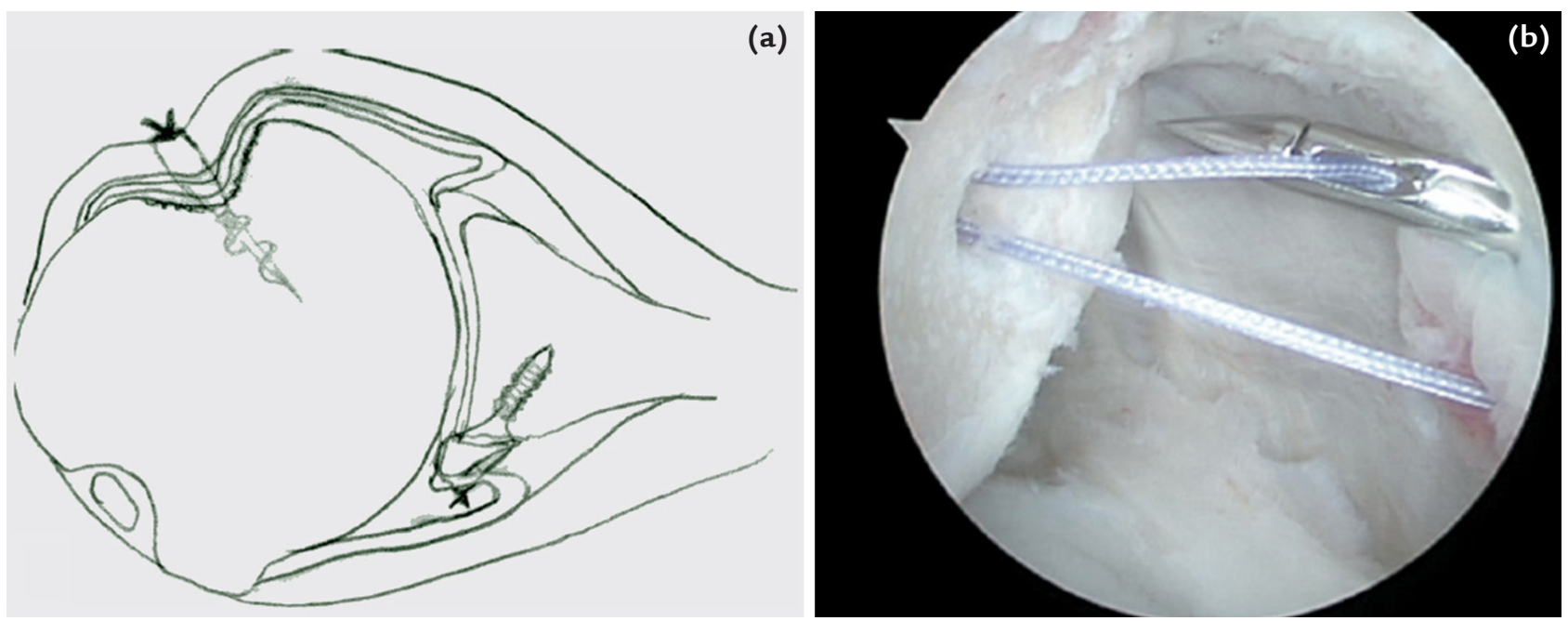

Şekil 8. a, b. Remplissage tekniğinin şematik çizimi (a) ve çapa yerleşiminin artroskopik görünümü (b) (Purchase ve ark. ${ }^{[31]}$ ).
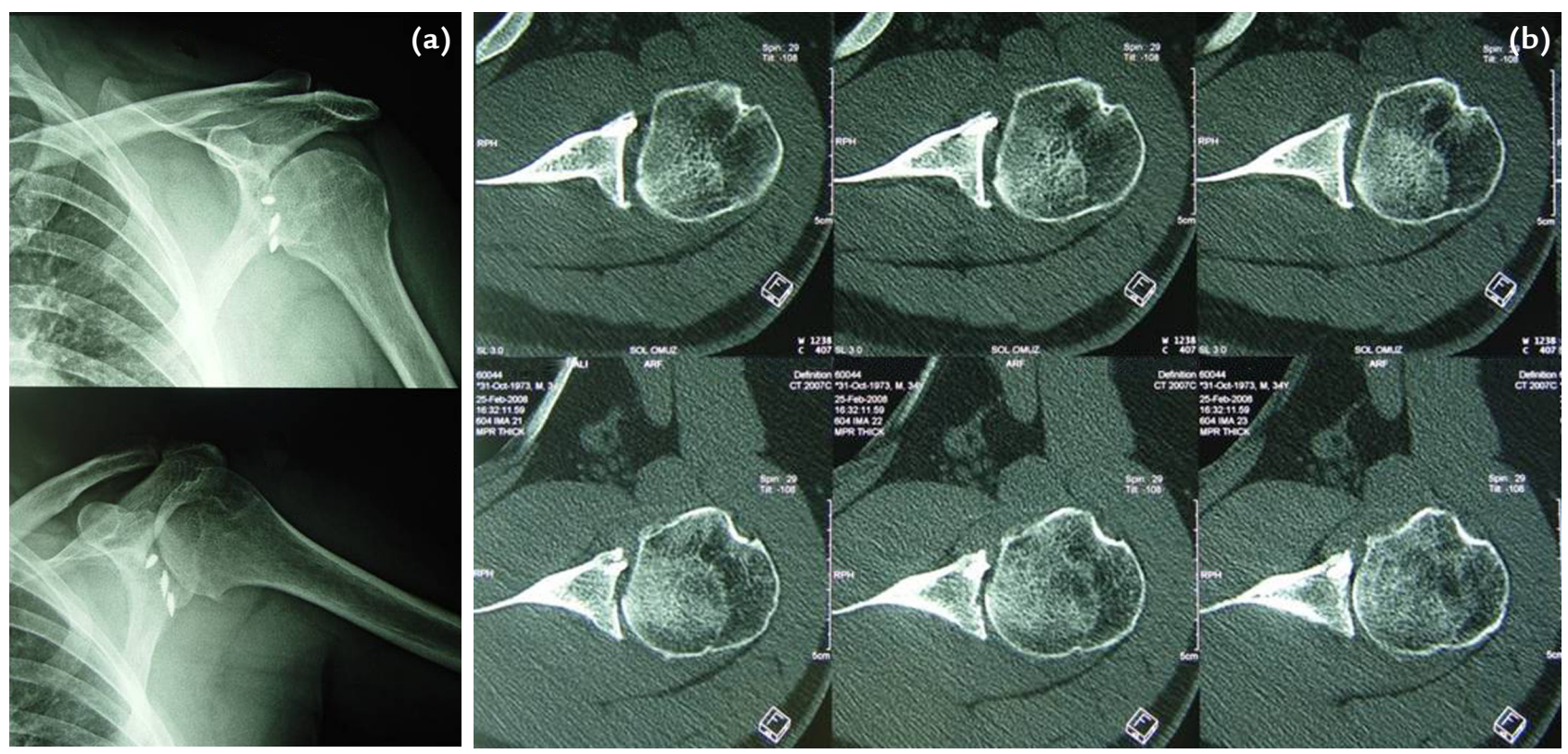

Şekil 9. Metalik çapa kullanılarak yapılan instabilite cerrahisinden sekiz ay sonraki röntgen kontrolü. Dejeneratif değişikliklerin kısa sürede geliştiği ve eklem uyumunun bozulduğu görülmekte.

\section{Hill-Sachs lezyonu}

Hill-Sachs lezyonu, anterior omuz çıkığı sonrasında, humerus başının posteriorunda meydana gelen çökmeyi tanımlamak için kullanılmaktadır. Anterior omuz instabilitesi bulunan hastalarda tanınmadığında, cerrahi sonrasında oluşan başarısızlık ve çıkıklarda önemi büyüktür. ${ }^{[7]}$

Remplissage tekniği Purchase ve ark. tarafından tanımlanan ve Hill-Sachs defektinin artroskopik olarak kapatılmasını sağlayan bir tekniktir. ${ }^{[31]}$ Fransızca "doldurmak" anlamına gelen "Reamplissage" tekniğinde, Hill-Sachs lezyonunun içerisine yerleştirilen iki adet çapa ile infraspinatus tendonu ve posterior kapsülün lezyona tenodezi ve kapsülodezi sağlanır (Şekil 8).

Son yıllarda orta ve uzun dönemde ortaya çıkan sorunlar nedeniyle metal çapalardan, bio-emilebilir çapalara doğru kayma olmaktadır. ${ }^{[32]}$ Bu değişimin nedeni glenohumeral çapa artropatisi olarak tanımlanan glenoid ve humerus başında lokal aşınma, kıkırdak kaybı, azalmış hareket açıklığı, mekanik semptomlar ve ağrıdır (Şekil 9). İlk kullanılan bio-emilebilir çapa Suretac (Acufex Microsurgical, Mansfield, MA) ile yabancı cisim reaksiyonları görülmüşş, ${ }^{[33]}$ implantın kırıldığı veya yerinden çıktığı seri bildirilmiştir. ${ }^{[34]}$ Tamamen polyglyconate 
(PGA) malzemeden imal edilen çapaların erken bozunduğu ve çekme kuvetini kaybettiği gösterilmiş̧ ${ }^{[35]}$ ve kısa zamanda üstünlükleri nedeniyle poly-L-lactic acid polymer (PLLA) çapalara geçiş olmuştur. ${ }^{[36]}$ Halen çapalara bağı problemler devam etmektedir. Osteoliz ve ortaya çıkan artropatinin mekanizması halen tam aydınlatılamamıştır ${ }^{\left[{ }^{[7]}\right.}$ ve glenoid osteonekrozu, ${ }^{[38]}$ osteoliz $^{[39]}$ gibi ciddi komplikasyonlar bildirilmektedir. Bugün bio-kompozit (PGA + PLLA) malzemeden çapalar üretilmektedir. Henüz uzun dönem sonuçları belirsiz olup, genç ve sağlam kemik yapısı olan hastalarda kırılma riski nedeniyle dikkatle kullanılması önerilmektedir. Son on yıllık çapa tecrübesi, önemli olan hangi malzemeden çapanın kullanıldığı değil, gerektiğinden fazla çapanın kullanılmaması gerektiğini göstermektedir.

Anterior instabilitede tedavi mutlaka, altta yatan Bankart lezyonunun dışında, kapsüler laksiteyi de içermelidir. Gevşek kapsül yapısının cerrahi sonrasında tekrarlayan subluksasyon ve dislokasyonların ortaya çıkışındaki önemi bir çok çalışmada gösterilmiştir. ${ }^{[40,41]}$ Bunun için iki farklı tedavi metodu önerilmektedir: Kapsüler plikasyon ${ }^{[42]}$ ve termal büzüştürme. ${ }^{[43]}$ Termal büzüştürmenin erken sonuçları olumluyken, günümüzde birçok kötü sonuç bildirilmiştir ve önerilmeyen bir yöntemdir. ${ }^{[44,45]}$

Rotator intervalin kapatılması 2000'li yıllarda oldukça popüler bir yöntemken, günümüzde çok daha nadiren uygulanmaktadır; posterior ve inferior instabilitede rolünün olmadığı gösterilmiştir, ancak anterior instabilite tedavisinde olumlu etkisi vardır. Eksternal rotasyonu belirgin kısıtlayan bir yöntem olduğu için, mutlaka cerrahi sırasında omuzun eksternal rotasyonunda yapılması önerilmektedir. ${ }^{[46]}$

\section{Rehabilitasyon}

Omuz instabilitelerinde rehabilitasyon süreci, cerrahi tedavinin tamamlayıcısı niteliğindedir ve mutlaka dikkatle uygulanmalıdır. Temel prensip, omuz ekleminin stabilizasyonunun desteklenmesi, skapulohumeral hareketin senkronizasyonu ve proprioseptif mekanizmanın restorasyonudur. Cerrahi teknik ve dikiş materyallerindeki gelişmeler sayesinde rehabilitasyon programları daha hızlı yürütülebilmektedir. Rehabilitasyon, mutlaka uygulanan cerrahi tipine ve kişinin aktivite düzeyine göre kişiselleştirilmelidir. ${ }^{[47]}$

\section{Başarısız cerrahiye etki eden faktörler}

İnstabilite cerrahisi sonrası başarısızlıkla ilişkili olduğu gösterilen sebepler; yırtığın şekli ve genişliği, ${ }^{[48]}$ kondral ve kemik defektler, ${ }^{[49]}$ teknik hatalar, ${ }^{\left[{ }^{[0]}\right]}$ yeterli yumuşak doku gerginliğinin sağlanamaması, ${ }^{[50]}$ Bankart $^{[2]}$ veya ALPSA $^{[1]}$ lezyonunun iyileşmemesi, cerrahi gereçlerdeki yetersizlik, ${ }^{[51,52]}$ hasta yaşı, ${ }^{[53]}$ cinsiyet, ${ }^{[54]}$ ailede anamnezi, ${ }^{[55]}$ kemik kalitesi, ${ }^{[56]}$ kişisel gelişim ve kontrol,[57] yüksek enerjili sportif aktivite, ${ }^{[58]}$ geçmiş immobilizasyon süresi ve dislokasyon sayısı, ${ }^{[50]}$ gecikmiş cerrahi, ${ }^{[50]}$ uygulanan rehabilitasyon programı, ${ }^{[59]}$ skapular kinematiğin bozulması ${ }^{[60]}$ olarak sıralanabilir.

ALPSA lezyonu olarak adlandırılan "anterior labroligamentous periosteal sleeve avulsion" yaralanması, Bankart lezyonundan farklı olarak, anterior labroligamentöz kompleksin çok daha mediale, glenoid boynuna yapışarak iyileşmesi ile karakterize bir lezyondur. Bu lezyonlar, instabilite cerrahisi sonrasında Bankart lezyonlarına göre iki kat daha fazla yinelenme göstermektedir. ${ }^{[61]}$

Cerrahi sonrası başarısızlık riski taşıyan hastalar önceden tanınmalı, tedavi ve rehabilitasyon protokolleri kişiselleştirilmelidir.

\section{Revizyon cerrahisi}

Geçmiş açık yapılan instabilite cerrahisi sonrasında revizyon oranları \%8 ila \%39 arasında bildirilmektedir. ${ }^{[29,62-65]}$

Literatürde ilk defa Kim ve ark. cerrahi sonrası yineleyen instabilitesi devam eden 23 hastanın artroskopik revizyon Bankart tamiri sonuçlarını yayımlamışlar, beş hastada yinelenme ile \%82 iyi-mükemmel sonuç bildirmişlerdir. ${ }^{[66]}$ Creighton ve ark. yaptıkları 18 artroskopik revizyon cerrahisi sonrasında, 5 başarısız sonuç ( 3 rekürren instabilite, 2 ağrı) bildirmişlerdir. ${ }^{[67]}$ Neri ve ark. İse, 11 hastada \%73 iyi-mükemmel sonuç bildirmişlerdir. ${ }^{[68]}$

Primer ve revizyon instabilite cerrahisi sonrası başarısız sonuçların gerekçeleri olarak, geniş Hill-Sachs lezyonları, temas sporları, yetersiz yumuşak doku örtüsü, artrozik değişiklikler, ameliyat sırasında yapılan teknik hatalar, ${ }^{[63]}$ uygunsuz ve yetersiz miktarda çapa kullanımı, anteroinferior kapsül hacminin yeteri kadar düşürülmemesi ${ }^{[68]}$ sayılabilir. Son sayılan iki gerekçe patolojik glenohumeral translasyona yol açmakta, bu da tespit yetmezliğine ve yinelenmeye gitmektedir. Yumuşak doku planlarının, özellikle anterior kapsül ve subskapularis arasının, anatominin bozulması nedeniyle tanınması zor olabilir.

Revizyon cerrahisi yapılan hastaların büyük bir çoğunluğunda kondral lezyonlara rastlanmaktadır. Ağrının devamına bağlı başarısız sonuçların altında yatan nedenlerden biri budur ve hastalar ameliyat öncesinde bu konuda uyarılmalıdırlar. ${ }^{63]}$

Yetersiz tedavi edilen osseöz defektler de başarısız sonuçların altta yatan nedenlerinden biridir. Gerektiğinde açık cerrahi uygulanmasından kaçınmamak gerekir. Altta yatan kemik defektin bulunduğu durumlarda, Bankart tamiri sonrası başarısız sonuçlar \%67 gibi yüksek bir 
değerde bildirilmekteyken, bu sayı temas sporlarıyla uğraşan atletlerde \%89'a kadar çıkmaktadır. ${ }^{[7]}$

\section{SONUÇ}

Tedavinin yönlendirilmesinde uygun muayene ve tetkikler ile instabilitenin altta yatan nedeni iyi aydınlatılmalıdır. Geçmişte artroskopik cerrahi ile yinelenme oranları açık cerrahiye göre daha yüksekken, yeni yayınlarda iki yöntem arasında fark yoktur. Açık ya da artroskopik cerrahi arasındaki tercih mutlaka hastaya göre kişiselleştirilmelidir. Amaç hastayı artroskopik olarak tedavi etmek değil, hastanın ihtiyaçlarına uygun şekilde tedavisini sağlamaktır. Dolayısıyla, tarif edilen tekniklerin endikasyonları çok iyi anlaşılmalı, cerrah gerektiğinde her tür yaklaşımı uygulayabilecek tecrübede olmalıdır.

\section{KAYNAKLAR}

1. Neviaser TJ. The anterior labroligamentous periosteal sleeve avulsion lesion: a cause of anterior instability of the shoulder. Arthroscopy 1993;9(1):17-21.

2. Blundell Bankart AS. The pathology and treatment of recurrent dislocation of the shoulder-joint. British Journal of Surgery 1938;26(101):23-39. CrossRef

3. Norlin R. Intraarticular pathology in acute, first-time anterior shoulder dislocation: an arthroscopic study. Arthroscopy 1993;9(5):546-9.

4. Taylor DC, Arciero RA. Pathologic changes associated with shoulder dislocations. Arthroscopic and physical examination findings in first-time, traumatic anterior dislocations. Am J Sports Med 1997;25(3):306-11.

5. Armfield DR, Stickle RL, Robertson DD, Towers JD, Debski RE. Biomechanical basis of common shoulder problems. Semin Musculoskelet Radiol 2003;7(1):5-18.

6. Calandra J, Baker CL, Uribe J. The incidence of Hill-Sachs lesions in initial anterior shoulder dislocations. Arthroscopy 1989;5(4):254-7.

7. Burkhart SS, De Beer JF. Traumatic glenohumeral bone defects and their relationship to failure of arthroscopic Bankart repairs: significance of the inverted-pear glenoid and the humeral engaging Hill-Sachs lesion. Arthroscopy 2000;16(7):677-94.

8. Matsen III FA, Lippit SB, Sidles JA, Harryman DT. Practical evaluation and management of the shoulder. Philadelphia: W. B. Saunders Company; 1994.

9. Belling Sørensen AK, Jørgensen U. Secondary impingement in the shoulder. An improved terminology in impingement. Scand J Med Sci Sports 2000;10(5):266-78.

10. Beltran J, Rosenberg ZS, Chandnani VP, Cuomo F, Beltran $S$, Rokito A. Glenohumeral instability: evaluation with MR arthrography. Radiographics 1997;17(3):657-73.

11. Elentuck D, Palmer WE. Direct magnetic resonance arthrography. Eur Radiol 2004;14(11):1956-67.

12. Blum $A$, Coudane $H$, Molé D. Gleno-humeral instabilities. Eur Radiol 2000;10(1):63-82

13. Sanders TG, Morrison WB, Miller MD. Imaging techniques for the evaluation of glenohumeral instability. Am J Sports Med 2000; 28(3):414-34.

14. Meister K. Injuries to the shoulder in the throwing athlete. Part one: Biomechanics/pathophysiology/classification of injury. Am J Sports Med 2000;28(2):265-75.
15. Lenters TR, Franta AK, Wolf FM, Leopold SS, Matsen FA 3rd. Arthroscopic compared with open repairs for recurrent anterior shoulder instability. A systematic review and meta-analysis of the literature. J Bone Joint Surg Am 2007;89(2):244-54.

16. Kropf EJ, Tjoumakaris FP, Sekiya JK. Arthroscopic shoulder stabilization: is there ever a need to open? Arthroscopy 2007;23(7):779-84.

17. Rhee YG, Lim CT, Cho NS. Muscle strength after anterior shoulder stabilization: arthroscopic versus open Bankart repair. Am J Sports Med 2007;35(11):1859-64.

18. Kang RW, Frank RM, Nho SJ, Ghodadra NS, Verma NN, Romeo AA, Provencher MT. Complications associated with anterior shoulder instability repair. Arthroscopy 2009;25(8):909-20. CrossRef

19. Kim TK, Queale WS, Cosgarea AJ, McFarland EG. Clinical features of the different types of SLAP lesions: an analysis of one hundred and thirty-nine cases. J Bone Joint Surg Am 2003;85-A(1):66-71.

20. Arrigoni P, Huberty D, Brady PC, Weber IC, Burkhart SS. The value of arthroscopy before an open modified latarjet reconstruction. Arthroscopy 2008;24(5):514-9. CrossRef

21. Burkart A, Imhoff $A B$. The suspension sling for arthroscopic fixation of SLAP lesions. Arthroscopy 2002;18(6):E33.

22. Dines JS, Elattrache NS. Horizontal mattress with a knotless anchor to better recreate the normal superior labrum anatomy. Arthroscopy 2008;24(12):1422-5. CrossRef

23. Edwards SL, Lee JA, Bell JE, Packer JD, Ahmad CS, Levine WN, Bigliani LU, Blaine TA. Nonoperative treatment of superior labrum anterior posterior tears: improvements in pain, function, and quality of life. Am J Sports Med 2010;38(7):1456-61. CrossRef

24. Imhoff AB, Ansah P, Tischer T, Reiter C, Bartl C, Hench M, Spang JT, Vogt S. Arthroscopic repair of anterior-inferior glenohumeral instability using a portal at the 5:30-o'clock position: analysis of the effects of age, fixation method, and concomitant shoulder injury on surgical outcomes. Am J Sports Med 2010;38(9):1795-803. CrossRef

25. Lo IK, Burkhart SS. Triple labral lesions: pathology and surgical repair technique-report of seven cases. Arthroscopy 2005;21(2):186-93.

26. Lafosse L, Lejeune E, Bouchard A, Kakuda C, Gobezie R, Kochhar T. The arthroscopic Latarjet procedure for the treatment of anterior shoulder instability. Arthroscopy 2007;23(11):1242.e1-5.

27. Lippitt SB, Vanderhooft JE, Harris SL, Sidles JA, Harryman DT 2nd, Matsen FA 3rd. Glenohumeral stability from concavitycompression: A quantitative analysis. J Shoulder Elbow Surg 1993;2(1):27-35. CrossRef

28. Provencher MT, Bhatia S, Ghodadra NS, Grumet RC, Bach BR Jr, Dewing CB, LeClere L, Romeo AA. Recurrent shoulder instability: current concepts for evaluation and management of glenoid bone loss. J Bone Joint Surg Am 2010;92 Suppl 2:133-51. CrossRef

29. Warner JJ, Gill TJ, O'hollerhan JD, Pathare N, Millett PJ. Anatomical glenoid reconstruction for recurrent anterior glenohumeral instability with glenoid deficiency using an autogenous tricortical iliac crest bone graft. The American journal of sports medicine 2006;34(2):205-12.

30. Lo IK, Parten PM, Burkhart SS. The inverted pear glenoid: an indicator of significant glenoid bone loss. Arthroscopy 2004;20(2):169-74.

31. Purchase RJ, Wolf EM, Hobgood ER, Pollock ME, Smalley CC. Hill-sachs "remplissage": an arthroscopic solution for the engaging hill-sachs lesion. Arthroscopy 2008;24(6):723-6. CrossRef 
32. Ozbaydar M, Elhassan B, Warner JJ. The use of anchors in shoulder surgery: a shift from metallic to bioabsorbable anchors. Arthroscopy 2007;23(10):1124-6.

33. Burkart A, Imhoff AB, Roscher E. Foreign-body reaction to the bioabsorbable suretac device. Arthroscopy 2000;16(1):91-5.

34. Sassmannshausen G, Sukay M, Mair SD. Broken or dislodged poly-L-lactic acid bioabsorbable tacks in patients after SLAP lesion surgery. Arthroscopy 2006;22(6):615-9.

35. Demirhan M, Kilicoglu O, Akpinar S, Akman S, Atalar AC, Göksan MA. Time-dependent reduction in load to failure of wedge-type polyglyconate suture anchors. Arthroscopy 2000;16(4):383-90.

36. Kilicoglu O, Demirhan M, Akman S, Atalar AC, Ozsoy S, Ince $U$. Failure strength of bioabsorbable interference screws: effects of in vivo degradation for 12 weeks. Knee Surg Sports Traumatol Arthrosc 2003;11(4):228-34.

37. Athwal GS, Shridharani SM, O'Driscoll SW. Osteolysis and arthropathy of the shoulder after use of bioabsorbable knotless suture anchors. A report of four cases. J Bone Joint Surg Am 2006;88(8):1840-5.

38. Smith MJ, Kane SM, Ingram EA, Propeck T. Osteonecrosis of the glenoid. A case report. J Bone Joint Surg Am 2006;88(8):1836-9.

39. Takubo Y, Morihara T, Namura T, Nakagawa H, Takeshita $\mathrm{H}$, Horii M, Kurokawa M, Kubo T. Anchor hole enlargement after arthroscopic Bankart repair using absorbable suture anchors: a report of three cases. J Shoulder Elbow Surg 2008;17(6):e16-8. CrossRef

40. Ahmad CS, Freehill MQ, Blaine TA, Levine WN, Bigliani LU. Anteromedial capsular redundancy and labral deficiency in shoulder instability. Am J Sports Med 2003;31(2):247-52.

41. Malicky DM, Kuhn JE, Frisancho JC, Lindholm SR, Raz JA, Soslowsky LJ. Neer Award 2001: nonrecoverable strain fields of the anteroinferior glenohumeral capsule under subluxation. J Shoulder Elbow Surg 2002;11(6):529-40.

42. Mclntyre LF, Caspari RB, Savoie FH 3rd. The arthroscopic treatment of multidirectional shoulder instability: twoyear results of a multiple suture technique. Arthroscopy 1997;13(4):418-25.

43. Hayashi K, Markel MD, Thabit G 3rd, Bogdanske JJ, Thielke RJ. The effect of nonablative laser energy on joint capsular properties. An in vitro mechanical study using a rabbit model. Am J Sports Med 1995;23(4):482-7.

44. Demirhan M, Uysal M, Kilicoglu O, Atalar AC, Sivacioglu S, Solakoglu S, Bozdag E, Sunbuloglu E. Tensile strength of ligaments after thermal shrinkage depending on time and immobilization: in vivo study in the rabbit. J Shoulder Elbow Surg 2005;14(2):193-200.

45. Chen S, Haen PS, Walton J, Murrell GA. The effects of thermal capsular shrinkage on the outcomes of arthroscopic stabilization for primary anterior shoulder instability. Am J Sports Med 2005;33(5):705-11.

46. Mologne TS, Zhao K, Hongo $M$, Romeo AA, An KN, Provencher MT. The addition of rotator interval closure after arthroscopic repair of either anterior or posterior shoulder instability: effect on glenohumeral translation and range of motion. Am J Sports Med 2008;36(6):1123-31. CrossRef

47. Akalin E, Gulbahar S, Kizil R. Rehabilitation of shoulder instability following surgery. Acta Orthop Traumatol Turc 2005;39 Suppl 1:109-18.

48. Spatschil A, LandsiedI F, Anderl W, ImhoffA, Seiler H, Vassilev I, Klein W, Boszotta H, Hoffmann F, Rupp S. Posttraumatic anterior-inferior instability of the shoulder: arthroscopic findings and clinical correlations. Arch Orthop Trauma Surg 2006;126(4):217-22.
49. Gill TJ, Warren RF, Rockwood CA Jr, Craig EV, Cofield RH, Hawkins RJ. Complications of shoulder surgery. Instr Course Lect 1999;48:359-74.

50. Porcellini G, Campi F, Pegreffi F, Castagna A, Paladini P. Predisposing factors for recurrent shoulder dislocation after arthroscopic treatment. J Bone Joint Surg Am 2009;91(11):2537-42. CrossRef

51. Meyer DC, Gerber C. Failure of anterior shoulder instability repair caused by eyelet cutout of absorbable suture anchors. Arthroscopy 2004;20(5):521-3.

52. Boileau P, Villalba M, Héry JY, Balg F, Ahrens P, Neyton L. Risk factors for recurrence of shoulder instability after arthroscopic Bankart repair. J Bone Joint Surg Am 2006;88(8):1755-63.

53. Postacchini F, Gumina S, Cinotti G. Anterior shoulder dislocation in adolescents. J Shoulder Elbow Surg 2000;9(6):470-4.

54. Loud KJ, Micheli LJ. Common athletic injuries in adolescent girls. Curr Opin Pediatr 2001;13(4):317-22.

55. Rowe CR. Prognosis in dislocations of the shoulder. J Bone Joint Surg Am 1956;38-A(5):957-77.

56. Good CR, MacGillivray JD. Traumatic shoulder dislocation in the adolescent athlete: advances in surgical treatment. Curr Opin Pediatr 2005; 17(1):25-9.

57. Huber $\mathrm{H}$, Gerber $\mathrm{C}$. Voluntary subluxation of the shoulder in children. A long-term follow-up study of 36 shoulders. J Bone Joint Surg Br 1994;76(1):118-22.

58. Handoll HH, Almaiyah MA, Rangan A. Surgical versus nonsurgical treatment for acute anterior shoulder dislocation. Cochrane Database Syst Rev 2004;(1):CD004325.

59. Kim SH, Ha KI, Jung MW, Lim MS, Kim YM, Park JH. Accelerated rehabilitation after arthroscopic Bankart repair for selected cases: a prospective randomized clinical study. Arthroscopy 2003;19(7):722-31.

60. Matias R, Pascoal AG. The unstable shoulder in arm elevation: a three-dimensional and electromyographic study in subjects with glenohumeral instability. Clin Biomech (Bristol, Avon) 2006;21 Suppl 1:S52-8.

61. Ozbaydar M, Elhassan B, Diller D, Massimini D, Higgins LD, Warner JJ. Results of arthroscopic capsulolabral repair: Bankart lesion versus anterior labroligamentous periosteal sleeve avulsion lesion. Arthroscopy 2008;24(11):1277-83. CrossRef

62. Rowe CR, Zarins B, Ciullo JV. Recurrent anterior dislocation of the shoulder after surgical repair. Apparent causes of failure and treatment. J Bone Joint Surg Am 1984;66(2):159-68.

63. Patel RV, Apostle K, Leith JM, Regan WD. Revision arthroscopic capsulolabral reconstruction for recurrent instability of the shoulder. J Bone Joint Surg Br 2008;90(11):1462-7. CrossRef

64. Zabinski SJ, Callaway GH, Cohen S, Warren RF. Revision shoulder stabilization: 2- to 10-year results. J Shoulder Elbow Surg 1999;8(1):58-65.

65. Levine WN, Arroyo JS, Pollock RG, Flatow EL, Bigliani LU. Open revision stabilization surgery for recurrent anterior glenohumeral instability. Am J Sports Med 2000;28(2):156-60.

66. Kim SH, Ha KI, Kim YM. Arthroscopic revision Bankart repair. Arthroscopy 2002;18(5):469-82.

67. Creighton RA, Romeo AA, Brown FM Jr, Hayden JK, Verma NN. Revision arthroscopic shoulder instability repair. Arthroscopy 2007;23(7):703-9.

68. Neri BR, Tuckman DV, Bravman JT, Yim D, Sahajpal DT, Rokito AS. Arthroscopic revision of Bankart repair. J Shoulder Elbow Surg 2007;16(4):419-24. 